\title{
Measurement of energy expenditure in the grazing ruminant
}

By F. G. Whitelaw, Rowett Research Institute, Bucksburn, Aberdeen AB2 ${ }_{9} S B$

Although our knowledge of the energy metabolism of farm livestock has advanced substantially during the last 20 years, we still know remarkably little about the energy expenditure or energy requirements of the grazing animal. Attempts to estimate these requirements have in the past relied upon two indirect approaches, the first based on the extrapolation of values obtained indoors by conventional calorimetric procedures and the second based on regression analyses of data relating to food intake, live weight and live-weight change of animals at pasture. Estimates obtained by the calorimetric approach have indicated that the energy expenditure of the grazing sheep may be from $10 \%$ to as much as $70 \%$ greater than that of the housed sheep (Blaxter, 1967 ; Graham, 1964a, $b$ ). By the second approach, estimates for maintenance of the grazing animal have ranged from values only slightly higher than those of housed animals (Corbett, Langlands \& Boyne, r96r; Langlands, Corbett, McDonald \& Reid, 1963 ) to some which are $2-3$ times as great (Coop \& Hill, I962; Hutton, I962; Lambourne \& Reardon, 1963; Arnold, McManus \& Dudzinski, 1965). Recent evidence suggests that many of these very high values are the result of errors in the measurement of herbage intake by the chromic oxide-faecal nitrogen method (Young \& Corbett, 1972a).

Because of the many assumptions involved in the calculations based on calorimetric data and the doubtful reliability of many of the techniques employed in grazing studies, much interest has been shown in the development of more direct methods of measuring energy expenditure in grazing ruminants. Much of the stimulus in these studies has come from workers in Australia, notably Leng and his colleagues at the University of New England and Corbett at the CSIRO Pasture Research Laboratory, Armidale, NSW. In a fruitful collaboration, these workers have pioneered and tested two of the most promising techniques to emerge in recent years. A discussion of these techniques and of their application and potential value will form the substance of this paper.

\section{Indirect calorimetry with tracheostomized animals}

Portable equipment for the measurement of respiratory exchange in humans has been available for many years and has been used to study the energy expenditure of subjects engaging in a wide variety of activities (Durnin \& Passmore, 1967). Basically the equipment consists of a mouthpiece or face-mask fitted with inlet and outlet valves, a gas meter for measuring the total volume of expired air and a device 
for removing and storing a representative fraction of air for subsequent analysis.

With grazing animals the use of a face mask is not feasible and resort must be made to fistulation of the trachea. Alternative procedures for this operation have been described by Colvin, Wheat, Rhode \& Boda (1957), and Blaxter \& Joyce ( 1963$)$. With both of these preparations the cranial portion of the trachea is occluded with a balloon when collections are made, with the result that $\mathrm{CO}_{2}$ and $\mathrm{CH}_{4}$ arising in the rumen are not included in the measurement of respiratory exchange. As discussed by Blaxter \& Joyce $\left(\mathrm{r}^{6} 6_{3}\right)$, tracheal fistulas of this type are difficult to maintain over long periods and survival rates are poor.

A method of fistulating the trachea which appears to overcome many of these disadvantages has been described by Young \& Webster ( 1963 ). This method involves a double tracheostomy and a re-entrant cannula containing inspiratory and expiratory valves which allows the animal to inhale normally and exhale through the distal tracheal fistula. Thus gases entering the trachea are warmed and humidified in the naso-pharynx and this is stated to prevent the disturbances of the respiratory pattern associated with intubation techniques. In addition, it is claimed that all eructated gases pass through the outlet valve and are recorded (Young \& Corbett, 1972b). Sheep prepared in this way have been maintained in good condition on pasture for periods of up to 4 years (Corbett, Leng \& Young, I969).

Flatt, Waldo, Sykes \& Moore ( $\left.195^{8}\right)$ have described a system for indirect calorimetry with grazing cows which employed the tracheal fistula of Colvin et al. (1957). In use, exhaled gases were passed through a modified Max-Planck meter (Müller \& Franz, 1952) attached to a harness on the animal's back. This harness also supported a 1001 Douglas bag in which a portion of expired air, usually $0.1 \%$ of the total flow, was collected over $6-12 \mathrm{~h}$ periods. The total weight of the equipment was $7 . I \mathrm{~kg}$. There do not appear to be any reports of the practical application of this equipment.

The use of indirect calorimetry in grazing sheep has been studied in some detail by the group at Armidale (Corbett et al. 1969; Young \& Corbett, 1972b). These workers have developed a system based on the re-entrant tracheal cannula of Young $\&$ Webster $\left(\mathrm{r}_{963}\right)$ in which the expired air is ducted along the shaft of a small twowheeled cart pulled by the animal. A Max-Planck gas meter and the sample storage containers are carried on the cart. Tests of this equipment, referred to as mobile indirect calorimetry (MIC), have been made within a closed-circuit respiration chamber (Graham, I962) and have shown the field equipment to underestimate $\mathrm{O}_{2}$ consumption and $\mathrm{CO}_{2}$ production by about $20 \%$ relative to the chamber measurements. In field studies the actual $\mathrm{O}_{2}$ and $\mathrm{CO}_{2}$ volumes are predicted from regression equations derived from the respiration chamber studies. Young \& Corbett (1972b) have estimated the maximum errors likely to arise in the calculation of energy expenditure values from the gaseous exchange data obtained from MIC equipment. The total error in the calculations, taken as the sum of the maximum errors for each factor involved, was $\pm 12 \cdot 3 \%$ and, of this, $97 \cdot 5 \%$ was associated with the measurement of the volume of expired air. Clearly, the gas metering equipment could well be improved and, in common with Flatt et al. (1958), the Australian workers con- 
sider that a flowmeter working on the principle of the integrating motor pneumotachograph (Wolff, I958) offers the greatest promise for future development.

In the practical application of the MIC equipment, the need for the animal to pull the cart presents some problems. Experiments on a treadmill have indicated that the energy cost of pulling the cart is low, amounting to about $96 \mathrm{~J} / \mathrm{d}$ for a $40 \mathrm{~kg}$ sheep, probably no more than $\mathrm{I}-2 \%$ of its total daily energy expenditure (Corbett, et al. 1969). The nature of the outdoor terrain and particularly the presence of tussocks or stones could obviously add considerably to these costs or, perhaps more likely, could result in an immobile sheep patiently awaiting rescue.

\section{Estimation of energy expenditure from measurements of $\mathrm{CO}_{2}$ entry-rate}

'The estimation of energy expenditure in grazing sheep by reference to the rate of formation of $\mathrm{CO}_{2}$ within the body (the so-called $\mathrm{CO}_{2}$ entry-rate) was first proposed by Young, Leng, White, McClymont \& Corbett (1969). These workers showed that $\mathrm{CO}_{2}$ entry-rates were correlated both with $\mathrm{CO}_{2}$ production and with total energy expenditure and that the technique was suitable for use on grazing animals. Since then further reports have appeared on the use of this method in sheep (Corbett, Farrell, Leng, McClymont \& Young, I971), in lambs (White \& Leng, I 968) and in cattle (Young, 1970) and in an independent study Whitelaw, Brockway \& Reid (I972) have examined the relationship between $\mathrm{CO}_{2}$ entry-rate, $\mathrm{CO}_{2}$ production and energy expenditure of sheep confined in respiration chambers.

The development of the $\mathrm{CO}_{2}$ entry-rate technique (referred to as CERT by the Australian workers) stemmed in part from earlier work by Annison, Brown, Leng, Lindsay \& West (1967). These workers administered a variety of ${ }^{14} \mathrm{C}$-labelled substrates to sheep and used the specific activity (SA) of $\mathrm{CO}_{2}$ in expired air to assess the contribution of each to total oxidative metabolism. It was reasoned therefore that if the total body pool of $\mathrm{CO}_{2}$ was labelled by administration of ${ }^{14} \mathrm{CO}_{2}$ then the SA of $\mathrm{CO}_{2}$ could yicld an index of total $\mathrm{CO}_{2}$ production, and hence of energy expenditure. When the labelled material, usually $\mathrm{NaH}^{14} \mathrm{CO}_{3}$, is given by continuous infusion and sufficient time is allowed for the infused ${ }^{14} \mathrm{CO}_{2}$ to attain equilibrium with the total body pool, or pools, of $\mathrm{CO}_{2}$, the rate of entry of metabolic $\mathrm{CO}_{2}$ into the body pool is given by the relationship

$$
\mathrm{CO}_{2} \text { entry-rate }(\mathrm{mmol} / \mathrm{min})=\frac{\text { Rate of infusion of activity }(\mu \mathrm{Ci} / \mathrm{min})}{\mathrm{SA} \text { of } \mathrm{CO}_{2}(\mu \mathrm{Ci} / \mathrm{mmol})},
$$

where the $\mathrm{SA}$ is that derived from the acid-labile $\mathrm{CO}_{2}$ present in blood, urine or other body fluid, or from exhaled gaseous $\mathrm{CO}_{2}$.

Measurements of $\mathrm{CO}_{2}$ entry-rate can be obtained also by a single-injection procedure (White \& Leng, I968) but this method requires very frequent sampling to define the slope of the SA-time curve and, because of the rapid elimination of ${ }^{14} \mathrm{CO}_{2}$ by the lungs, is useful only for short-term measurements of metabolism.

Practical details of the procedures involved in the measurement of $\mathrm{CO}_{2}$ entryrates have been given by Corbett $e t$ al. (1971) and Whitelaw et al. (1972). Under 
field conditions the choice of sample for radioassay is usually restricted to blood or urine. Of these, urine is probably the more convenient as it is secreted continuously and appears to yield an integrated value for SA over the period of collection. Urine samples can be obtained with ease from female animals by means of an indwelling bladder catheter, and simple battery-operated proportioning devices have been developed to allow continuous sampling (Young, r970; A. J. F. Russel, personal communication). An automatic device for withdrawing blood samples at frequent intervals has also been developed (Farrell, Corbett \& Leng, I970) and lightweight infusion pumps which can be carried by sheep or cattle have been described by Leng, Corbett \& Brett (I968) and Treacher (1973).

\section{Route of infusion and equilibration time}

In the studies reported to date, a subcutaneous route of infusion has been most widely employed (Young et al. 1969; Corbett et al. I97r; Whitelaw et al. 1972). This method, however, has been found to result occasionally in a 'pooling' of infusate beneath the skin and cannot be recommended. Young (I970) favours an intraperitoneal route for infusions in cattle although Whitelaw et al. (1972) experienced difficulty with this method in sheep. Corbett et al. (I97I) and Whitelaw et al. (I972) have found intravenous infusions to be both convenient and reliable and to suffer few of the disadvantages inherent in other methods.

There appears to be some uncertainty regarding the time required for the equilibration of the infused activity with the body pool of $\mathrm{CO}_{2}$. Thus Young et al. (1969) and Corbett et al. (197I) considered $3 \mathrm{~h}$ to be sufficient for the equilibration of $\mathrm{CO}_{2}$ in the blood of sheep when infusions were given subcutaneously or intraperitoneally, whereas Whitelaw et al. (1972) found with subcutaneous infusions that at least $8 \mathrm{~h}$ were required for reasonably constant $\mathrm{SA}$ values to be recorded in blood and urine. Young ( 1970 ) allowed $4^{-5} \mathrm{~h}$ in his work with cattle infused intraperitoneally. On the basis of the rather limited evidence available on the transfer of $\mathrm{CO}_{2}$ between the various body compartments in the ruminant (Hoernicke, Williams, Waldo \& Flatt, 1965; Annison et al. 1967) it is my view that 3 h is insufficient for equilibration and that the procedure adopted by Whitelaw et al. ( 1972$)$, who allowed $\mathrm{r} 2 \mathrm{~h}$ for preliminary equilibration, has much to commend it.

\section{Choice of sample}

The choice of sampling site and the interpretation of differing SA values obtained from different sites has been discussed at length by Corbett et al. (I97I) and by Young (1970). Briefly these workers consider that local differences in the production and elimination of $\mathrm{CO}_{2}$ can result in differences in $\mathrm{SA}$ value between various tissues and body fluids and that both the choice of sampling site and the choice of infusion route will influence the estimate of $\mathrm{CO}_{2}$ entry-rate. 'They argue further that there need not be uniformity of SA throughout the body, even though the SA reaches a plateau when one particular compartment is sampled.

These suggestions contrast markedly with observations on the transport and 
distribution of ${ }^{14} \mathrm{CO}_{2}$ in dogs, cats and rats. In these species the $\mathrm{SA}$ of expired $\mathrm{CO}_{2}$ has been shown to equal that of blood $\mathrm{CO}_{2}$ (Kornberg, Davies \& Wood, 1952; Robinson \& Coxon, 1957; Coxon \& Robinson, I959) and the bicarbonate of blood is known to equilibrate rapidly with a larger pool which probably includes all the extracellular bicarbonate (Shipley, Baker, Incefy \& Clark, 1959). In sheep also, the $\mathrm{SA}$ of blood $\mathrm{CO}_{2}$ has been shown to reach an equilibrium with urinary $\mathrm{CO}_{2}$ within a few h of the start of infusion (Whitelaw et al. 1972). Short-term variations in SA undoubtedly occur in each of the body compartments and are particularly noticeable in blood and expired air (Morris \& Simpson-Morgan, 1963) but these almost certainly reflect minute-by-minute changes in the metabolic or physical activity of the animal rather than a disequilibrium between pools.

In non-ruminant species the major disequilibrium with respect to the $\mathrm{SA}$ of $\mathrm{CO}_{2}$ is that between bone and extracellular fluid. In addition to being the largest single pool of $\mathrm{CO}_{2}$ in the body, bone carbonate is known to have a very low rate of turnover (Fahri \& Rahn, I960) and probably reaches equilibrium with body ${ }^{14} \mathrm{CO}_{2}$ only after several weeks of continuous administration (Buchanan \& Nakao, 1952). The possible retention of ${ }^{14} \mathrm{C}$ in the skeleton of sheep in experiments of short duration has been discussed by Whitelaw et al. ( $197^{2}$ ), who considered that retention might account for some $2-4 \%$ of the ${ }^{14} \mathrm{C}$ infused.

The arguments put forward by Corbett et al. (197I) are undoubtedly valid in relation to the rumen pool of $\mathrm{CO}_{2}$, which is continually diluted by $\mathrm{CO}_{2}$ arising during the microbial fermentation of the food. Although the extent of this dilution will vary throughout the day, depending on the pattern of food intake, it is unlikely that rumen ${ }^{14} \mathrm{CO}_{2}$ ever reaches an equilibrium with ${ }^{14} \mathrm{CO}_{2}$ in other body compartments. As indicated by Young ( 1970 ), rumen fluid must be considered unsuitable as a source of ${ }^{14} \mathrm{CO}_{2}$ in $\mathrm{CO}_{2}$ entry-rate studies.

Of the other body fluids available for sampling, milk is considered unsuitable on account of its acidic nature and low $\mathrm{CO}_{2}$ content (Ling, Kon \& Porter, 196r). Low and variable $\mathrm{SA}$ values for $\mathrm{CO}_{2}$ isolated from milk have been reported by Young ( 1970 ). In practice, the choice of sample is usually restricted to blood or urine and, as indicated earlier, urine has the advantage of being secreted continuously and hence of providing an integrated value for SA over the period of collection.

\section{The relationship between $\mathrm{CO}_{2}$ entry-rate and $\mathrm{CO}_{2}$ production}

Regression equations describing the relationship between estimates of $\mathrm{CO}_{2}$ entryrate and simultaneous measurements of $\mathrm{CO}_{2}$ production have been presented by White \& Leng (1968), Corbett et al. (1971) and Whitelaw et al. (1972). In every instance $\mathrm{CO}_{2}$ entry-rates overestimated actual $\mathrm{CO}_{2}$ production: in the Australian work this overestimation ranged from $9 \%$ in the work of White \& Leng (1968) to values of ${ }_{18-} 31 \%$, depending on the sampling site, in the experiments reported by Corbett. In the more detailed study of Whitelaw et al. (1972), $\mathrm{CO}_{2}$ entry-rates were found to overestimate production by only $2-4 \%$ and this was considered to be due to the retention in bone of this amount of infused radioactivity. Whitelaw and his colleagues 
concluded that $\mathrm{CO}_{2}$ entry-rates could provide a reliable measure of $\mathrm{CO}_{2}$ production.

In attempting to explain the discrepancies between the estimated and actual values for $\mathrm{CO}_{2}$ production in their own work, Corbett and co-workers introduced the arguments outlined above regarding non-uniform distribution of label throughout the body compartments and differences between routes of infusion and sampling sites. They concluded that $\mathrm{CO}_{2}$ entry-rates did not provide a measure of the rate of $\mathrm{CO}_{2}$ production but were probably some function of $\mathrm{CO}_{2}$ production and, as such, could provide a useful index of energy expenditure. They stipulated however that the methods of infusion and of sampling used in deriving the prediction equations must be identical to those employed in the application of the technique in field studies.

These views and conclusions of Corbett et al. (197 I) were, of course, based entirely on their inability to achieve some measure of equality between $\mathrm{CO}_{2}$ production and $\mathrm{CO}_{2}$ entry-rates. In the light of the more recent work of Whitelaw et al. (1972) it seems likely that the discrepancies observed by the Australian workers stemmed largely from the difficulties experienced in measuring $\mathrm{CO}_{2}$ production under field conditions, using the MIC equipment described above. Possible changes in the body stores of $\mathrm{CO}_{2}$ during their $\mathrm{I} h$ periods of observation would also contribute to errors in the measured values for $\mathrm{CO}_{2}$ output (Fahri \& Rahn, I960; Kleiber, 1961).

In contrast, the experiments of Whitelaw et al. (1972) were conducted over $24 \mathrm{~h}$ periods in a closed-circuit respiration chamber in which the total $\mathrm{CO}_{2}$ produced was absorbed in $\mathrm{KOH}$ and determined gravimetrically (Wainman \& Blaxter, 1969). Thus it can be suggested that experiments designed to examine the relationship between $\mathrm{CO}_{2}$ entry-rates and $\mathrm{CO}_{2}$ production should meet three basic requirements: (1) before measurements begin sufficient time must be allowed for the infused ${ }^{14} \mathrm{CO}_{2}$ to equilibrate with all body pools of $\mathrm{CO}_{2}$, except bone; (2) the measurements must be made over sufficient time for the effect of transient changes in body $\mathrm{CO}_{2}$ stores to be minimized; and (3) the equipment used for the measurement of respiratory exchange must have an inherent accuracy better than that expected of the $\mathrm{CO}_{2}$ entry-rate technique.

\section{The relationship between energy expenditure and $\mathrm{CO}_{2}$ entry-rate}

Some of the relationships which have been presented in the literature are shown in Fig. I. It is evident that major differences exist between the relationships proposed by different workers but, as discussed in the preceding section, much of this variability probably arises from inadequacies both in the methods employed and in the duration of the observations.

Since there is evidence that $\mathrm{CO}_{2}$ entry-rates can be equated with $\mathrm{CO}_{2}$ production it follows that energy expenditure can be derived directly from entry rates by reference to a known or assumed value for respiratory quotient (RQ) and the appropriate energy value of $\mathrm{CO}_{2}$. The energy equivalent of $\mathrm{CO}_{2}$ varies by about $30 \%$ over the range of $\mathrm{RQ}$ from 0.7 to $\mathrm{I} \cdot \mathrm{O}$ (Brody, I 945), hence errors in the value adopted 


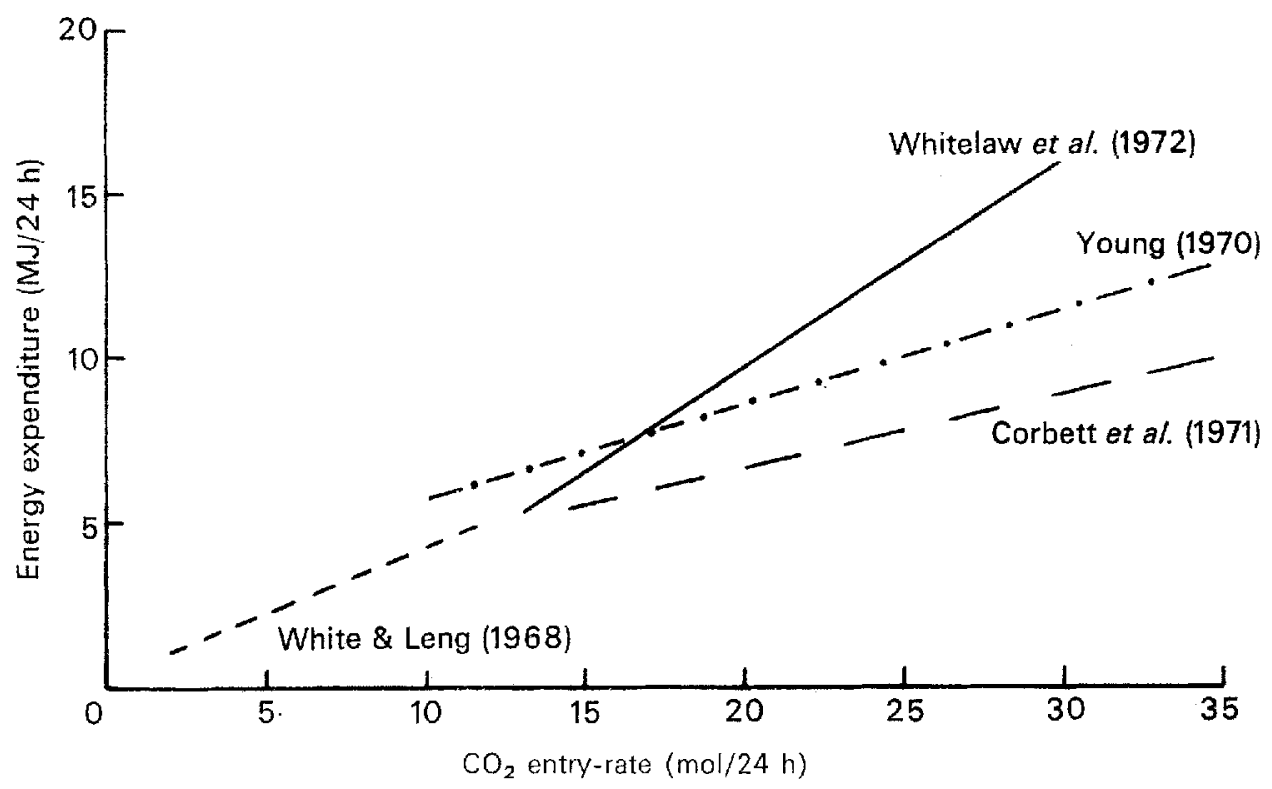

Fig. 1 . The relationships between energy expenditure and $\mathrm{CO}_{2}$ entry-rate reported by White \& Leng (1968) for young milk-fed lambs, by Corbett, Farrell, Leng, McClymont \& Young (1971) and Whitelaw, Brockway \& Reid (1972) for sheep and by Young (1970) for both sheep and cattle.

for RQ could lead to substantial errors in the estimation of energy expenditure. While the precise significance of $\mathrm{RQ}$ values in ruminant species is a matter of debate, there is evidence from a great number of calorimetric studies that $\mathrm{RQ}$ values in mature sheep kept indoors and given a wide variety of conventional diets normally fall within the range 0.9 to $I \cdot I$. Values between 0.9 and 0.8 occur infrequently, while values below 0.8 appear to be found only in animals fasted for more than $48 \mathrm{~h}$. Within this upper range of $\mathrm{RQ}$ values the variation in the energy equivalent of $\mathrm{CO}_{2}$ is less than $10 \%$ and hence the errors associated with an estimate of energy expenditure based on an assumed $\mathrm{RQ}$ within this range should be no greater. Thus, in the study of Whitelaw et al. (1972) the actual RQ was 0.9r; if, however, we adopt an assumed $\mathrm{RQ}$ of $\mathrm{I} \cdot \mathrm{O}$ and apply the appropriate energy equivalent to the measured values for $\mathrm{CO}_{2}$ entry-rate, the energy expenditure values so obtained differ from those derived from the regression equation by only $+7 \%$ to $-9 \%$ over the range in entry-rates from ${ }_{5} 5$ to $25 \mathrm{~mol} / 24 \mathrm{~h}$. The magnitude of these errors is rather less than the residual errors of the regression equations proposed by the Australian workers (Fig. I). Whether a similar precision could be achieved by use of this assumed $\mathrm{RQ}$ value in grazing sheep subjected to daily variations in food intake and physical activity, and possibly in climatic stress, remains to be established.

\section{Some recent applications of these techniques}

Corbett et al. (I97I) have reported results of short-term measurements of $\mathrm{CO}_{2}$ entry-rates in sheep exercised intermittently on a treadmill. Each increase or decrease in activity was reflected in an increase or decrease in entry-rate some 
IO-20 min later and approximate calculations indicated that estimates of the energy cost of horizontal locomotion derived in this way were similar to those reported by Clapperton (1964) for sheep exercised within a respiration chamber.

In a more extensive study, Young \& Corbett (1972a,b) have estimated the energy requirements of grazing sheep by the use of both the MIC technique and $\mathrm{CO}_{2}$ entry-rates. Three groups of sheep were kept at constant live weights of 45,35 and $25 \mathrm{~kg}$ for several months and estimates of energy expenditure were calculated from the entry-rate values by reference to the relationships proposed by Corbett $e t$ al. (1971), derived under similar conditions. In general, estimates of daily energy expenditure obtained by the MIC technique were in good agreement with those obtained from entry-rate measurements: this alone cannot be considered as evidence for the validity of either technique, of course, since the relationships employed in the entry-rate work were originally derived in calibration tests employing the MIC equipment as reference (Corbett et al. 1971). Compared with values for housed sheep, the estimated maintenance requirements of grazing sheep were greater by $43-64 \%$ when they were in full-fleece and by $56-91 \%$ after shearing. These values are in reasonable agreement with values that can be predicted by the summation of the energy costs of the various activities of grazing sheep (Graham, $1964 b$ ).

The only reports of the use of the $\mathrm{CO}_{2}$ entry-rate technique on grazing cattle are those of Young (1970), in which the values reported are $0.59^{-0.77} \mathrm{MJ} / \mathrm{kg}^{0.75}$ per $\mathrm{d}$ for 2-year-old cows with calves and $0.68-0.73 \mathrm{MJ} / \mathrm{kg}^{0.75}$ per $\mathrm{d}$ for young growing heifers.

\section{Conclusions}

There seems little doubt that the $\mathrm{CO}_{2}$ entry-rate technique shows the greatest potential promise as a method of estimating energy expenditure in grazing ruminants. Much will depend, however, on the outcome of further studies on the precise relationship between $\mathrm{CO}_{2}$ entry-rates and energy expenditures; if this relationship differs widely in different situations, as is suggested by some of the published evidence, the application of the technique will obviously be limited and will be confined to those centres which are able to calibrate the method by reference to independent measurements of energy expenditure. Some of the criteria to be considered in the calibration procedures have been outlined above and it is to be hoped that adherence to these criteria will in time yield a more generalized relationship suitable for application under a wide variety of circumstances.

Eventually, the validity of $\mathrm{CO}_{2}$ entry-rate measurements must be tested under field conditions against a reliable alternative method of measuring energy expenditure. It would appear that the methods of mobile indirect calorimetry devised by Flatt et al. (19.5) and Corbett et al. (1969), with some improvements in the precision of the gas metering equipment, would be most suited to limited applications of this nature.

Finally, it must be emphasized that the measurement of energy expenditure in grazing animals cannot be an end in itself. Under most systems of husbandry, 
animals at pasture increase in live weight or produce wool or milk or are pregnant, and the energy cost of these processes must be considered along with energy expenditure in arriving at estimates of requirements or in assessing the productivity of pastures. This, in turn, requires a knowledge of energy intake and it is imperative that studies on the grazing ruminant should encompass techniques not only for estimating energy expenditure but also for providing estimates of herbage intake and for assessing changes in body composition during growth. Ideally, these measurements should be supplemented with observations on grazing behaviour and activity patterns and on those characteristics of the outdoor environment which can be measured.

\section{REFERENCES}

Annison, E. F., Brown, R. E., Leng, R. A., Lindsay, D. B. \& West, C. E. (1967). Biochem. F. xо4, I35. Arnold, G. W., McManus, W. R. \& Dudzinski, N. L. (1965). Aust. F. exp. Agric. Anim. Husb. 5, 396. Blaxter, K. L. (1967). The Energy Metabolism of Ruminants and ed. London: Hutchinson.

Blaxter, K. L. \& Joyce, J. P. (1963). Br. F. Nutr. I7, 523.

Brody, S. (r945). Bioenergetics and Growth. New York: Reinhold Publishing Corp.

Buchanan, D. L. \& Nakao, O. (1952). F. biol. Chem. 198, 245.

Clapperton, J. L. (1964). Br. F. Nutr. 18, 47.

Colvin, H. W., Wheat, J. D., Rhode, E. A. \& Boda, J. M. (1957). F. Dairy Sci. 40, 492.

Coop, I. E. \& Hill, M. K. (I962). F. agric. Sci., Camb. 58, i 87.

Corbett, J. L., Langlands, J. P. \& Boyne, W. A. (r96r). Proc. VIIIth int. Congr. Anim. Prod., Hamburg, p. 245 .

Corbett, J. L., Leng, R. A. \& Young, B. A. (1969). Publs Eur. Ass. Anim. Prod. no. 12, p. 177.

Corbett, J. L., Farrell, D. J., Leng, R. A., McClymont, G. L. \& Young, B. A. (197 I). Br. J. Nutr. 26, 277.

Coxon, R. V. \& Robinson, R. J. (I959). F. Physiol., Lond. r47, 469.

Durnin, J. V. G. A. \& Passmore, R. (1967). Energy, Work \& Leisure. London: Heinemann.

Fahri, L. E. \& Rahn, H. (1960). Anesthesiology 2r, 604.

Farrell, D. J., Corbett, J. L. \& Leng, R. A. (1970). Res. vet. Sci. I1, 217.

Flatt, W. P., Waldo, D. R., Sykes, J. F. \& Moore, L. A. (r958). Publs Eur. Ass. Anim. Prod. no. 8, p. ror.

Graham, N. McC. (1962). Proc. Aust. Soc. Anim. Prod. 4, 138.

Graham, N. McC. (1964a). Aust. F. agric. Res. 15, 969.

Graham, N. McC. (1964b). Proc. Aust. Soc. Anim. Prod. 5, 272.

Hoernicke, H., Williams, W. F., Waldo, D. \& Flatt, W. P. (1965). Publs Eur. Ass. Anim. Prod. no. I 1, p. 165.

Hutton, J. B. (I962). Proc. N.Z. Soc, Anim. Prod. 22, 12.

Kleiber, M. (196I). The Fire of Life p. 88. New York: John Wiley \& Sons.

Kornberg, H. L., Davies, R. E. \& Wood, D. R. (1952). Biochem. F. 51, 35 1.

Lambourne, L. J. \& Reardon, 'T. F. (1963). Aust. $\mathscr{~}$. agric. Res. 14, 272.

Langlands, J. P., Corbett, J. L., McDonald, I. \& Reid, G. W. (1963). Anim. Prod. 5, II.

Leng, R. A., Corbett, J. L. \& Brett, D. J. (1968), Br. F. Nutr. 22, 57.

Ling, E. R., Kon, S. K. \& Porter, J. W. G. (1961). In Milk: the Mammary Gland and its Secretion Vol. 2, p. 227 [S. K. Kon and A. T. Cowie, editors]. London: Academic Press.

Morris, B. \& Simpson-Morgan, M. W. (r963). F. Physiol., Lond. r69, 713.

Müller, E. A. \& Franz, H. (I952). Arbeitsphysiologie r5, 499.

Robinson, R. J. \& Coxon, R. V. (1957). Nature, Lond. 180, 1279.

Shipley, R. A., Baker, N., Incefy, G. E. \& Clark, R. E. (I959). Am. F. Physiol. 197, 41.

Treacher, R. J. (1973). Vet. Rec. 93, 596.

Wainman, F. W. \& Blaxter, K. L. (I969). Publs Eur. Ass. Anim. Prod. no. I z, p. 429.

White, R. G. \& Leng, R. A. (1968). Proc. Aust. Soc. Anim. Prod. 7, 335.

Whitelaw, F. G., Brockway, J. M. \& Reid, R. S. (r972). Q. fl exp. Physiol. 57, 37.

Wolff, H. S. (1958). Q. fl exp. Physiol. 43, 270.

Young, B. A. (1970). In Energy Metabolism of Farm Animals p. 237 [A. Schürch and C. Wenk, editors]. Zurich: Juris Druck Verlag. 
Young, B. A. \& Corbett, J. L. (1972a). Aust. Y. agric. Res. 23, 77.

Young, B. A. \& Corbett, J. L. (1972b). Aust. Y. agric. Res. 23, 57.

Young, B. A., Leng, R. A., White, R. G., McClymont, G. L. \& Corbett, J. L. (1969). Publs Eur. Ass. Anim. Prod. no. 12, p. 435.

Young, B. A. \& Webster, M. E. D. (1963). Aust. 7 . agric. Res. 14, 687. 